\title{
Compact tri-band T-shaped frequency reconfigurable antenna for cognitive radio applications
}

\author{
Abdullah A. Jabber, Raad H. Thaher \\ Department of Electrical Engineering, Al Mustansiriyh University, Baghdad, Iraq
}

\begin{tabular}{l}
\hline \hline Article Info \\
\hline Article history: \\
Received Aug 19, 2019 \\
Revised Oct 12, 2019 \\
Accepted Dec 14, 2019 \\
\hline
\end{tabular}

\section{Keywords:}

Broadband

Cognitive radio

CST

PIN diode

Reconfigurable antenna

Ultra wideband

VSWR

\begin{abstract}
This paper presents, new compact tri-band and broadband frequency reconfigurable antenna for cognitive radio applications. The proposed antenna consists of an Ultrawideband sensing antenna and reconfigurable communicating antenna at the same substrate. The sensing antenna is a UWB printed elliptical monopole antenna operates at frequency band from 2.72 to $23.8 \mathrm{GHz}$ which can cover the entire UWB frequency band from 3.1 to $10.6 \mathrm{GHz}$ and cover the broadband up to $20 \mathrm{GHz}$. The communicating antenna is a T-shaped frequency reconfigurable antenna operates on three bands of $7.925 \mathrm{GHz}, 13.16 \mathrm{GHz}$, and $14.48 \mathrm{GHz}$ under $(\mathrm{S} 11 \leq-10 \mathrm{~dB})$ with a fractional bandwidth of $14.55 \%, 6.2 \%$, and $3.3 \%$ respectively. The proposed antenna used to operate in two modes one for cognitive radio applications to cover WiMAX, land, Fixed and Mobile satellite, Radar, and broadband applications. The frequency reconfigurability is obtained by using only one RF switch (PIN diode) for changing the operating frequency. The antenna overall dimensions are $42 \times 30 \times 1.6 \mathrm{~mm}^{3}$ printed on an FR-4 epoxy substrate with relative dielectric constant $\varepsilon \mathrm{r}=4.3$, loss tangent $\tan (\delta)=0.002$ and $50 \Omega$ microstrip line feed. The maximum obtained simulated gain is $8.5 \mathrm{~dB}$ at $13.16 \mathrm{GHz}$. The $\mathrm{S} 11$ is under $-20 \mathrm{~dB}$ and coupling between the two antennas is less than $-15 \mathrm{~dB}$ at the resonant frequencies.
\end{abstract}

This is an open access article under the CC BY-SA license.

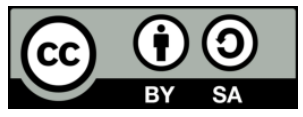

Corresponding Author:

Abdullah Ali Jabber,

Department of Electrical,

Al Mustansiriyh University, Baghdad, Iraq.

Email: aalhusseini742@gmail.com

\section{INTRODUCTION}

The demand for frequency bands causes the available RF spectrum becomes utilized owing to the development of communication systems in the latest years. This utilization makes shortage in the frequency bands because of the incompetent spectrum allocation management policies, where $70 \%$ of the allocated licensed spectrum remains unused noted by the Federal Communications Commission (FCC) in November 2002 [1]. The cognitive radios (CRs) are smart communication systems constructed on a software-defined radio platform, attempt to get better spectral utilization by dynamic interaction with the RF environment and they have the ability to learn from their environment and be familiar with the changes of their surrounds. The CR system has a process of adaptation which consists of operational parameters updating like modulation strategy, carrier frequency, transmission data rate and transmits power in response to the observed RF environment. The main objectives of the cognitive radios (CRs) can be explained in two points, the first one is the assurance of the communication reliability whenever and wherever needed, and the second is the efficient utilization of the radio spectrum [1-2]. The main incentive of the CR technology is the improvement and optimization of spectrum utilization because 
of the $90 \%$ of the time the offered channels are ideally free. The CR functioning consists of three main steps, they are spectrum sensing, analysis, decision, and mobility which can be shown in [3].

In the network of the CR system, in order to reduce the interference between primary and secondary users to a minimum, the secondary users (unlicensed users) have the permission to access the spectrum bands of the primary users (licensed users). There are three types of spectrum sharing between primary and secondary users, they are spectrum underlay, spectrum overlay, and spectrum interwave techniques. In the underlay a pproach, secondary users must operate below the noise floor of primary users, and thus strict constraints are imposed on the transmission power. Ultra-wideband (UWB) technology is very appropriate for this approach. In spectrum overlay CR, secondary users do search for unused bands of frequency and use them for communication. In the interwave CR, the system allows the secondary users to efficiently utilize the unused spectrum holes while avoiding or limiting, collisions with primary transmissions [1]. To share the spectrum with licensed users without interference with them, and satisfy the various QoS requirements of applications, each CR user in a CR network should perform Spectrum Sensing, Spectrum intelligence or decision, Spectrum Sharing, and Spectrum mobility. Spectrum sensing refers to sense and decides the portion of spectrum that is available free. Spectrum decision refers to selecting the available channel, and this is known as Spectrum decision and Spectrum sharing refers to let the other users share the available channel, and Spectrum mobility refers to make the channel free when a licensed user is detected" [3-5].

Sensing and communicating antennas are the basic RF structure of a CR system, where the sensing antenna always a UWB antenna used for wireless channel continuous monitoring of unutilized frequency bands, while the communicating antenna performs the communication through those channels [6]. There a re four techniques applied to produce frequency reconfigurable antennas, they are electrical, optical, physical, and smart materials reconfigurations. The electrical reconfiguration is attained by $\mathrm{RF}$ switches such as MEMS, PIN, and varactor diodes, while an optical reconfigurations use photoconductive switching elements such as silicon switches. Structural adjustment of the antenna using slots, cuts, etc. is used for physical reconfiguration, while the smart materials reconfigurability can be implemented using smart materials such as ferrites, liquid crystals, etc.[7-8].

The cognitive radio antenna design can be classified into three main parts, the first and the second classes are two ports one for UWB sensing antenna and the second for communicating antenna for the electrical and mechanical reconfigurations, while the third class is a single port of a UWB/narrowband antenna with reconfigurable slots [3-4]. In [9-10], a CR system is presented based on two-port mechanical reconfigurability wherein [9] the sensing UWB and reconfigurable antennas are fabricated on the same substrate. The antenna uses an egg-shaped UWB sensing antenna and stepper motor to rotate five patches of the communicating antenna to produce five resonance frequencies of (3.44, 4.5, 5.36, 7.29, and 10.2) $\mathrm{GHz}$. The peak gain obtained is 11.17 at $5.36 \mathrm{GHz}$ and coupling less than $-20 \mathrm{~dB}$. In [10], also an egg-shaped UWB sensing antenna being used and five communicating patches are rotated for frequency reconfigurability of the whole $2-10 \mathrm{GHz}$.

In [11-12], a CR antenna of two ports based on an electrical reconfigurable antenna is proposed. In [11], the antenna comprises a UWB sensing antenna of half egg-shaped with a reconfigurable monopole antenna. Three switches are used for frequency tuning with frequency bands of $(3.7$ to $4.2 \mathrm{GHz}$, 5 to $5.85 \mathrm{GHz}$, and 7.46 to $8.5 \mathrm{GHz}$ ). The isolation between the two antennas is better than $-10 \mathrm{~dB}$. In [12], the antenna supports frequency reconfigurability from 5-6 GHz. The antenna gain and mutual coupling between the sensing and communicating antenna are $0.5 \mathrm{dBi}$ and less than $-20 \mathrm{~dB}$ respectively.

In [13-20], the proposed CR systems based on single port UWB antenna with reconfigurable slots and switches between them for frequency reconfigurability. In [13], a UWB antenna with T-shaped slot placed between pair of symmetrical gaps with six electronic switches to produce bandpass structure for frequency tuning from 6-9 GHz with a peak gain of $5.4 \mathrm{~dB}$ at 7.6 $\mathrm{GHz}$. In [14], a UWB antenna with four slots and ring slot with two electronic switches for frequency reconfiguration. The resonance frequencies of $2.75,2.9,3.7,4.4$, and $4.6 \mathrm{GHz}$ for two states. In [15], a UWB antenna with six parasitic coplanar elements connected by six electronic switches to produce six bands with frequency reconfigurability range from 6.4-12 GHz. In [16], the designed semicircular shaped UWB antenna with a T-shaped slot filter with six switches in the feeding for adjusting the bandwidth to select sub-band and pre-filter the others. The six cases of the switches produce six reconfigurable bands from 5-10 GHz and the peak gain is $4.14 \mathrm{~dB}$. In [17], a compact UWB antenna with reconfigurable band-notched with two switches for frequency tuning from 3.3 to $4.1 \mathrm{GHz}$. The peak average gain is $3 \mathrm{~dB}$. In [18], two configurations of a UWB reconfigurable antenna were having the same patch but different GND plane with five and six PIN diodes respectively. The first design can operate in UWB, single, and double bands, while the second design also operat es in three modes but more cases than the first one. Both structures operate with frequency reconfigurability from 5-9 GHz. In [19], a UWB and double bands frequency reconfigurable antenna are presented. By using 
the circular patch with $\mathrm{C}$ slot attached with rectangular L-shaped and defected ground plane and inserting two parasitic surfaces the antenna operates with frequency reconfigurability range from $2.8-5.94 \mathrm{GHz}$.

In [20-23], reconfigurable MIMO antennas for CR applications. In [20-21], a compact multi-band frequency reconfigurable antenna is presented. The antenna comprises two elements and four elements integrated with PIN and varactor diodes. According to the states of the PIN diode and controlling the bias voltage of the varactor diode the antenna operates with frequency tuning from $(0.573-2.48) \mathrm{GHz}$ and (0743-2.42) $\mathrm{GHz}$ with peak gain and isolation of $3.15 \mathrm{~dB}, 3.52 \mathrm{~dB}$ and better than $-15 \mathrm{~dB}$ respectively. In [22], a MIMO antenna is suggested for CR applications. The antenna consists of two arrangements of patches the first comprises two reconfigurable antennas with four PIN diodes between the T-shaped slots for frequency tuning while the other is two sensing antennas which cover the band from 3-6 GHz. The maximum coupling between the elements is better than -15 dB. In [23], a MIMO antenna is designed for the CR system. A wideband structure in the middle is used to enhance the isolation between the two antenna elements. The sensing antenna can cover two bands one for the lower band of $2.3-6.3 \mathrm{GHz}$ and the other for the higher band from 2.2-7 GHz. The antenna can tune the operating frequency from 2.3-6.3 GHz by using two pairs of varactor diodes.In this paper, compact multiband two ports inverted-L/T-shaped antenna is proposed for cognitive radio (CR) applications and some other wireless applications such as WiMAX, Radar, land, Fixed and Mobile Satellite applications.

\section{PROPOSED COGNITIVE RADIO ANTENNA DESIGN AND PIN DIODE MODELING}

\subsection{Proposed CR antenna design}

The overall structure of the proposed antenna that illustrates the front and back views is shown in Figure 1. The front side of the antenna consists of UWB printed elliptical monopole antenna and T-shaped microstrip reconfigurable communicating antenna. The backside of the antenna shows partial ground for both structures, where the UWB sensing antenna has a partial elliptical ground plane (GND plane) and the communicating antenna has a rectangular partial ground plane. The two structures are printed on FR 4 epoxy substrate with 4.3 dielectric constant, height (h) $1.6 \mathrm{~mm}$, loss tangent of 0.002 as used in [24, 25], and overall dimensions of $42 \mathrm{~mm} \times 30 \mathrm{~mm}$. The design equations of the communicating antenna can be listed at equations from (1) to (5) respectively, while the sensing antenna design according to (6) and (7) respectively [26].

$$
\begin{aligned}
& \mathrm{W}=\frac{\mathrm{V} 0}{2 f r} \sqrt{\frac{2}{\varepsilon r+1}} \\
& \varepsilon e f f=\frac{\varepsilon r+1}{2}+\frac{\varepsilon r-1}{2}\left[1+12 \frac{h}{w}\right]^{-\frac{1}{2}} \\
& \Delta \mathrm{L}=0.412 \mathrm{~h} \frac{(\text { rreff }+0.3)\left(\frac{w}{h}+0.264\right)}{(\varepsilon r e f f-0.258)\left(\frac{w}{h}+0.8\right)} \\
& L e f f=L+2 \Delta L \\
& L=\frac{V 0}{2 f r \sqrt{\varepsilon e f f}}-2 \Delta L \\
& a=\frac{F}{\left\{1+\frac{2 h}{\pi \varepsilon r F}\left[\left[\ln \left(\frac{\pi F}{2 h}\right)+1.7726\right]\right\}^{\frac{1}{2}}\right.} \\
& F=8.791 * \frac{10^{9}}{f r \sqrt{\varepsilon r}}
\end{aligned}
$$

where: $\mathrm{W}=$ the width of the patch

$$
\mathrm{V} 0=\text { velocity of light }
$$

$\varepsilon r=$ the dielectric constant

$\mathrm{fr}=$ the resonant frequency

greff=the effective dielectric constant

$\mathrm{h}=$ the substrate height

$\Delta \mathrm{L}=$ length due to the fringing effect

Leff $=$ the effect patch and

$\mathrm{L}=$ the actuallength of the patch

$\mathrm{a}=$ the radius of the circular patch 


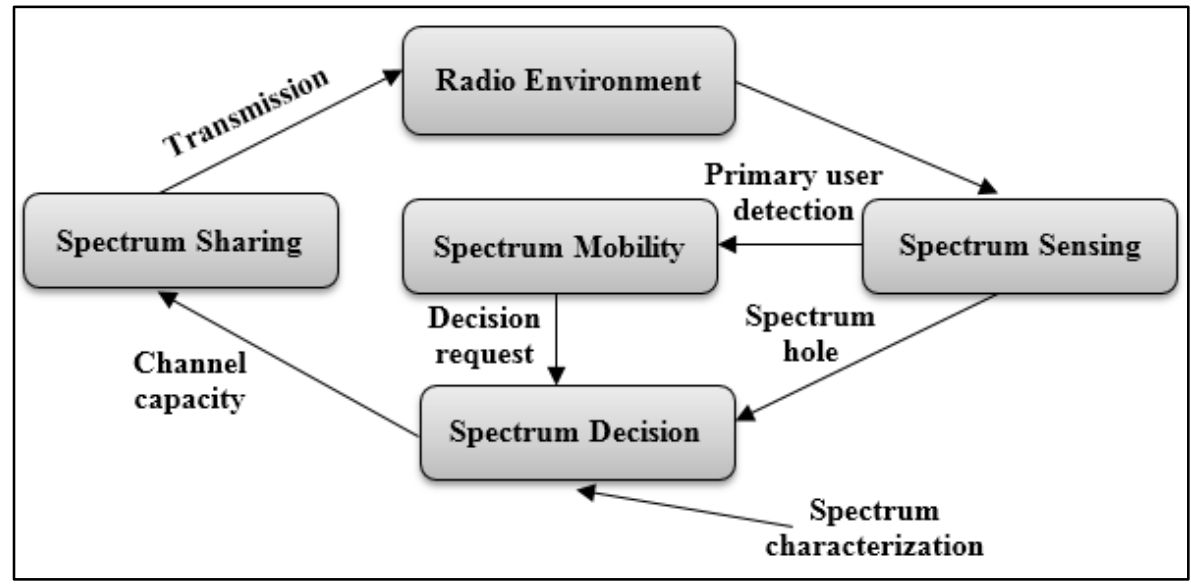

Figure 1. Cognitive radio functioning flow chart [3]

\subsubsection{UWB sensing antenna design}

The structure of the UWB sensing antenna is an elliptical printed monopole antenna that can be shown in Figure 2(a) and(b). The optimized antenna operates with a frequency band that covers the UWB from (3.1-10.6) $\mathrm{GHz}$ and cover the broadband up to $17 \mathrm{GHz}$ so that the proposed antenna shape is chosen and optimized parameters are shown in Table 1. The antenna consists of an elliptical monopole patch of $(10 \mathrm{~mm}, 7 \mathrm{~mm})$ radii, $50 \Omega$ microstrip line feed and a half elliptical ground plane of $(15 \mathrm{~mm}, 7 \mathrm{~mm})$ radii.

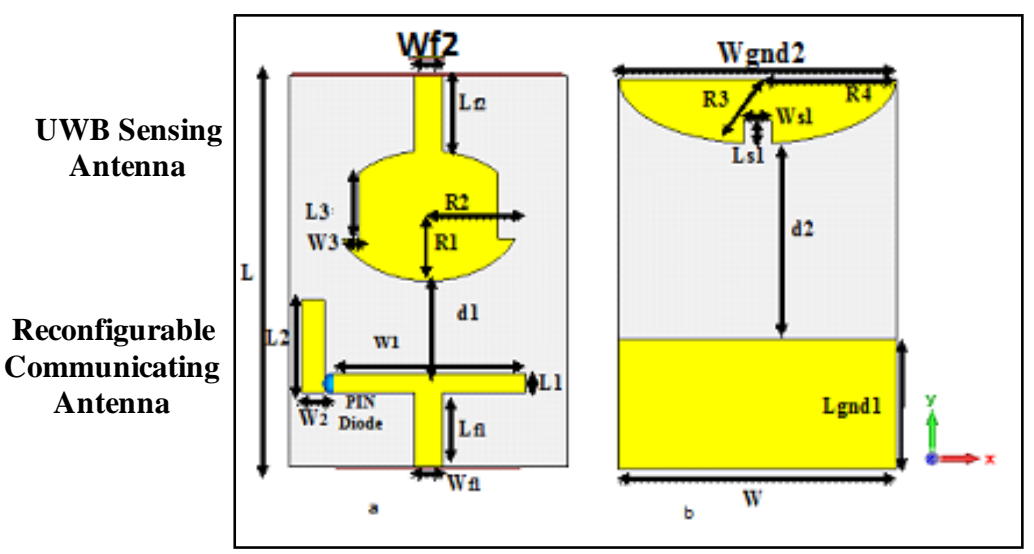

Figure 2. The proposed multi-band cognitive radio antenna, (a) Front side, and (b) Backside

Table 1. The optimum parameters of CR antenna

\begin{tabular}{cccccc}
\hline Parameters & Values in mm & Parameters & Values in mm & Parameters & Values in mm \\
\hline W & 30 & Wf1 & 3 & R4 & 15 \\
L & 42 & Wf2 & 3 & Ls 1 & 3 \\
L1 & 2 & Lgnd1 & 14 & Ws 1 & 3 \\
W1 & 21 & t & 0.035 & d1 & 10 \\
L2 & 10 & h & 1.6 & Lf1 & 8 \\
W2 & 2.5 & R1 & 10 & Lf2 & 8.1 \\
L3 & 7.13 & R2 & 7 & Wgnd2 & 30 \\
W3 & 2.5 & R3 & 7 & Wgnd 1 & 30 \\
Ld & 0.7 & d2 & 21 & & \\
\hline
\end{tabular}

\subsubsection{Communicating antenna design}

The proposed design of the Tri-band reconfigurable $\mathrm{T}$-shaped antenna can be shown in Figure 2(a) and(b). After the study of the latest researches and determine which applications to cover by the antenna the proposed antenna shape is chosen after some para metric study of the patch and GND plane 
dimensions to be completely different from the literature. The overall patch dimensions are $10 \mathrm{~mm} \times 21 \mathrm{~mm}$, which is compact and suitable for many wireless applications. All optimum parameters of the a ntenna are summarized in Table 1. The antenna has only single (DSM8100-000 Mesa Beam-Lead) from Skyworks PIN diode used to modify the length of the proposed inverted-L antenna to reconfigure the resonant frequency to meet other bands of frequencies. The PIN diode is placed in an optimized position to achieve the desired operation.

\subsection{Pin diode modelling}

The states of the electronic switch are ON and OFF. They can be realized by biasing the PIN diode in the forward or reverse bias. At the ON state, the switch is forward bias and it has low impedance acts as a short circuit and the current can pass through the diode, while in the OFF state the switch is reversed bias and it presents a high impedance and acts as an open circuit which indicates no current flown through the diode. An electrical circuit is shown in Figure 3, which explain the forward and reverse biased, where the only resistor of $(3.5 \mathrm{ohms})$ in series with an inductor of $(0.15 \mathrm{nH})$ in the ON state and a combination of $(1 \mathrm{Kohm})$ resistor in parallel with the capacitance of $(0.025 \mathrm{pF})$ all in series with an inductor of $(0.15 \mathrm{nH})$ [27]. The PIN diode is modeled in the CST simulation by using RLC Lumped elements and inserting the values of the diode resistance, capacitance, and inductance according to the ON/OFF-sta tes of the PIN diode.

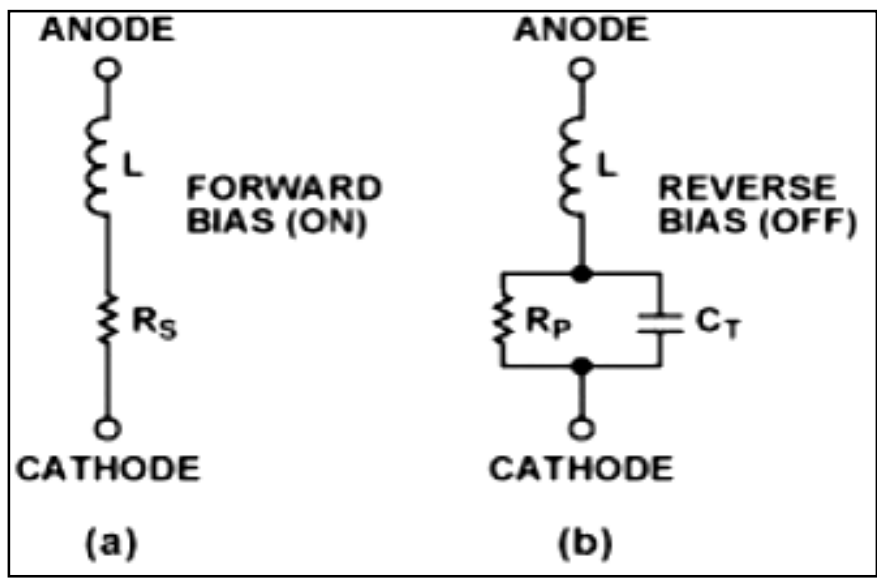

Figure 3. PIN diode modeling under, (a) Forward, (b) Reversed biased condition

\section{RESULTS AND DISCUSSION}

The CST software is used to simulate the proposed cognitive radio antenna. The simulated (S11) of the UWB sensing antenna can be shown in Figure 4(a), which has an operating band cover the UWB (3.1-10.6) GHz and cover the band up to $17 \mathrm{GHz}$. The obtained Tri-bands with the (S11) through the two states of the PIN diode is pragmatically shown in Figure 4(b), where obtained lowest S11 of (-43 dB) in the $(13.16 \mathrm{GHz})$. There are three frequency bands under the $(\mathrm{S} 11 \leq-10 \mathrm{~dB})$ condition have resulted in the ON and OFF states of the PIN diode, they are $7.825 \mathrm{GHz}, 13.16 \mathrm{GHz}$, and $14.48 \mathrm{GHz}$, which are applicable to cover WiMAX, Radar, land, Fixed and Mobile Satellite systems. The two bands (7.925 and 14.48) $\mathrm{GHz}$ are resulted from the $\mathrm{ON}$ state, while a band of (13.16) GHz is obtained from the OFF state of the PIN diode.

The simulated coupling coefficient (S12) between the two antennas is illustrated in Figure 5, where the lowest coupling is less than $-29 \mathrm{~dB}$ at $13.16 \mathrm{GHz}$. The gain is ranging from $(4.6$ to 8.5$) \mathrm{dBi}$ as shown in Figure 6. The simulated VSWR of the proposed CR antenna meet the practical requirements of (VSWR $\leq 2$ ) at all the resulted multiband frequencies, where the VSWR is a measure for how the line is matching with the load.The (2D/3D) radiation pattern and (3D) surface current distribution of the proposed CR are shown in Figure 7 and Figure 8 respectively, they represent the 2D/3D results. The surface current distribution presented in Figure 8(b) shows the OFF state of the PIN diode where no current flown to the second arm of the patch, while the other states present the ON state. The proposed antenna can be compared with the literature to produce the strength of the system and is listed in Table 2. 


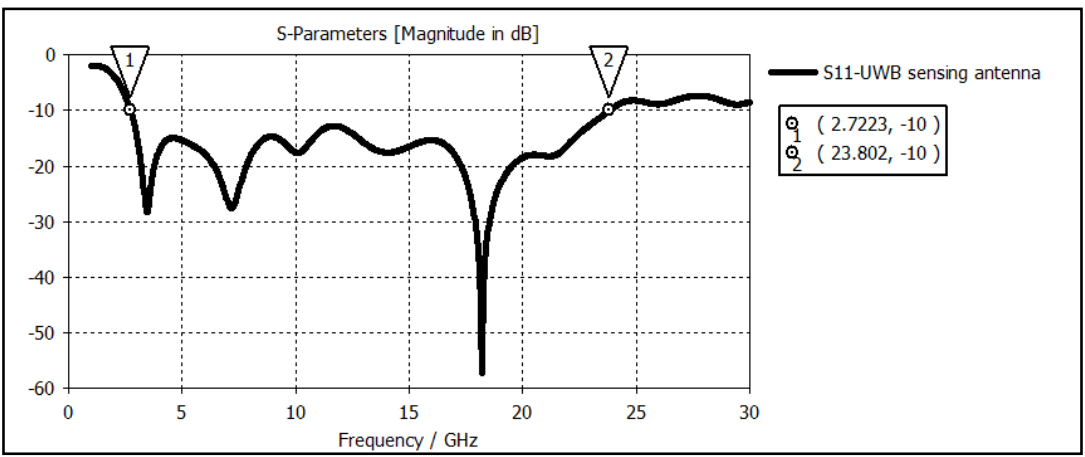

(a)

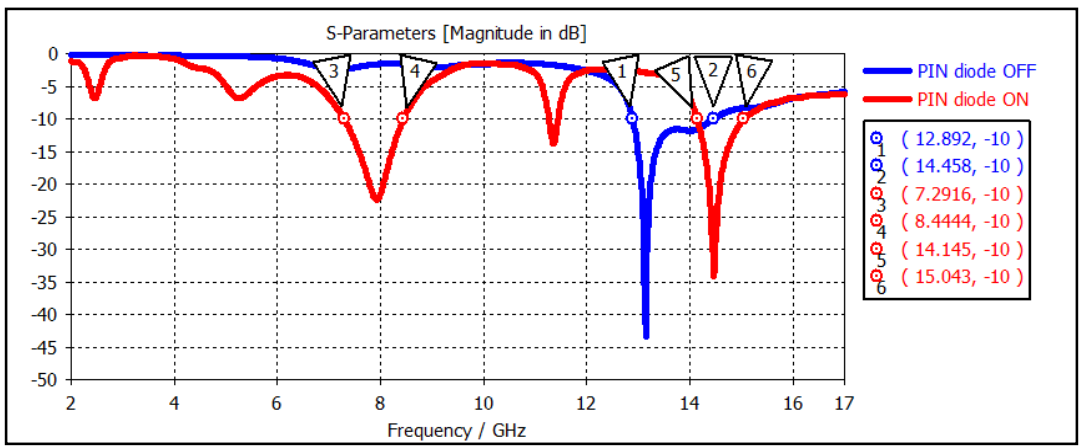

(b)

Figure 4. (a) The simulated (S11) parameter versus frequency of the UWB sensing antenna, (b)The simulated (S11) parameter versus frequency of the communicating antenna

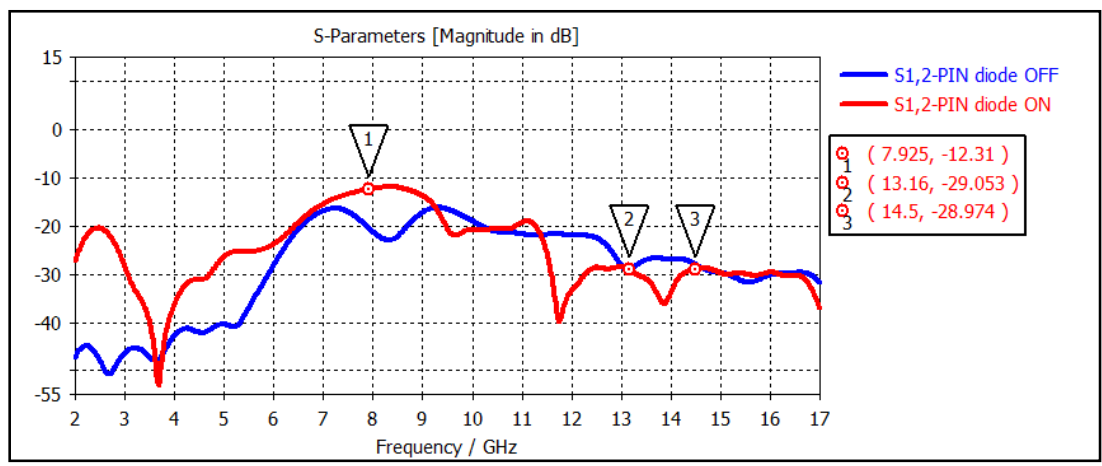

Figure 5. The simulated (S12) parameter (Coupling effect) between the two antennas versus frequency

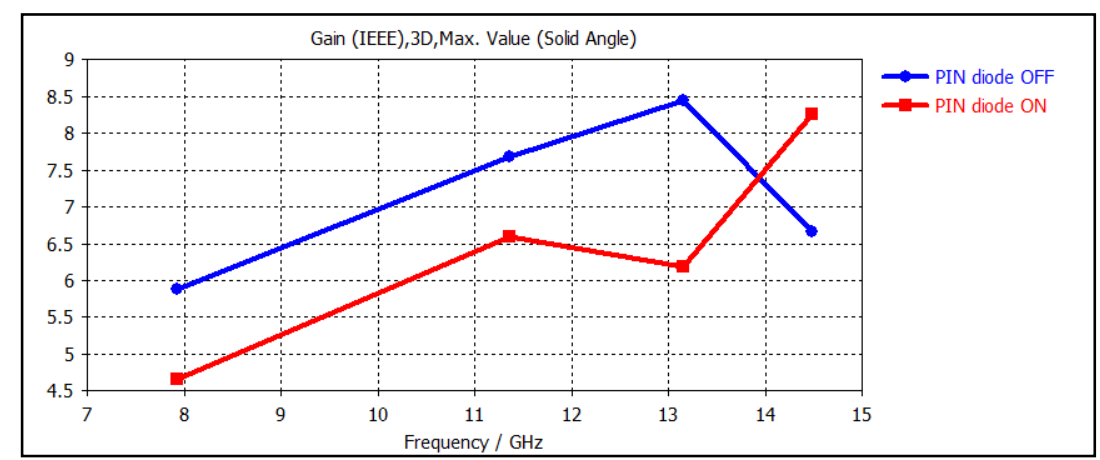

Figure 6. The gain variation with the frequency of the CR antenna 


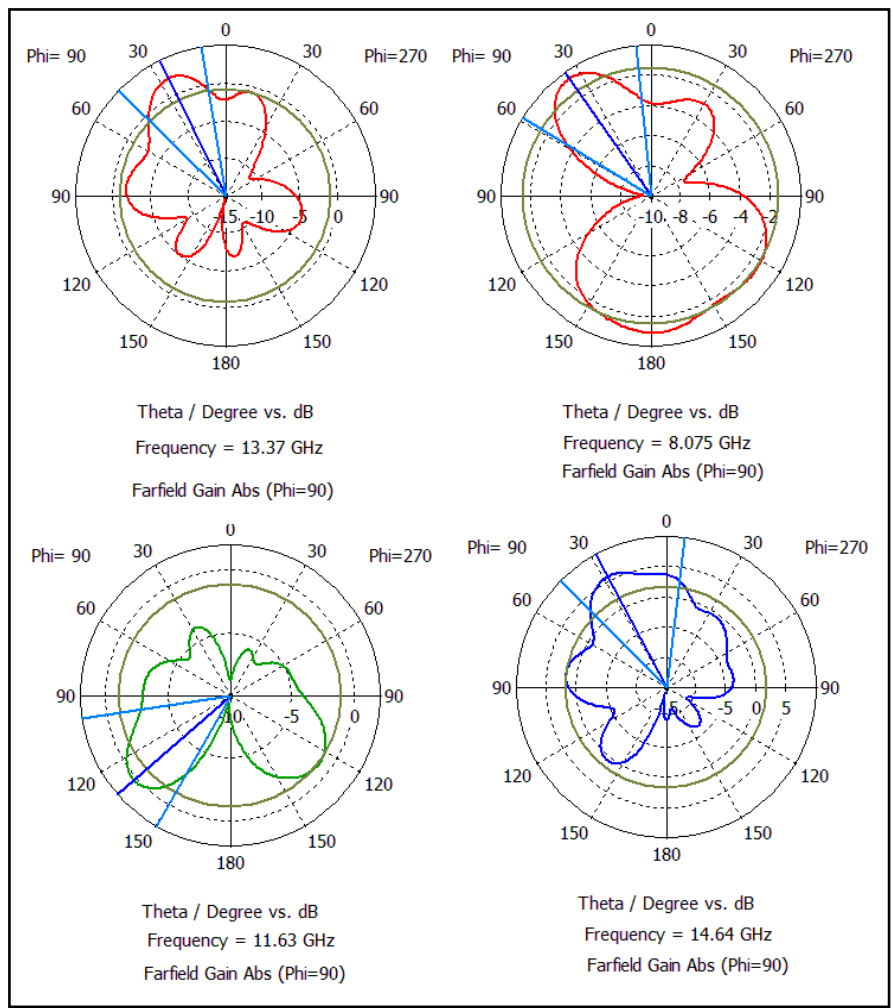

(a)

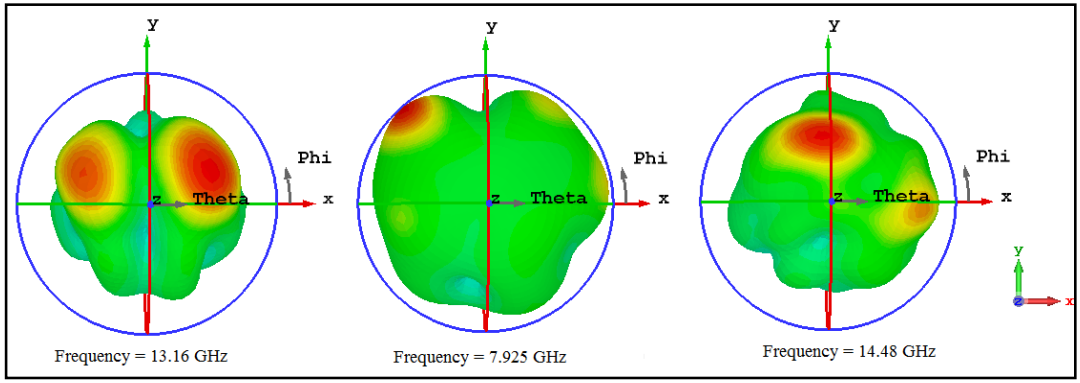

(b)

Figure 7. The (2D/3D) CR antenna radiation pattern, (a) 2D radiation pattern, (b) 3D radiation pattern

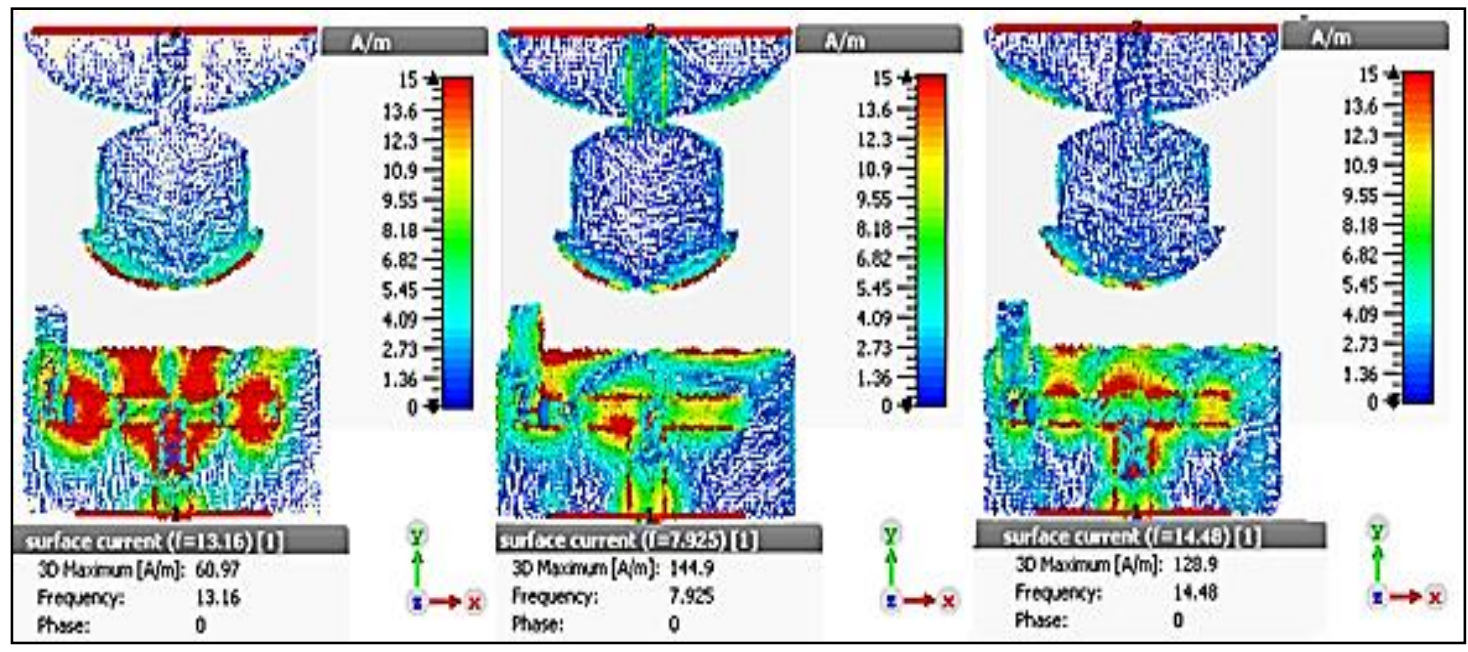

Figure 8. The (3D) CR antenna surface current distribution 
Table 2. A comparison between the proposed CR antenna and the literature

\begin{tabular}{|c|c|c|c|c|c|c|c|}
\hline References & $\begin{array}{c}\text { Type of The } \\
\text { Antenna }\end{array}$ & $\begin{array}{c}\text { No. of } \\
\text { Switches }\end{array}$ & $\begin{array}{c}\text { Type of } \\
\text { Reconfigurability }\end{array}$ & $\begin{array}{l}\text { UWB Sensing } \\
\text { Antenna B.W } \\
\quad(\mathrm{GHz})\end{array}$ & $\begin{array}{c}\text { Frequency } \\
\text { Bands } \\
(\mathrm{GHz})\end{array}$ & $\begin{array}{l}\text { Peak } \\
\text { gain } \\
(\mathrm{dB})\end{array}$ & $\begin{array}{l}\text { Max. } \\
\text { Isolation } \\
\text { (dB) }\end{array}$ \\
\hline 9 & Two ports & ----- & $\begin{array}{c}\text { Rotating by Stepper } \\
\text { motor }\end{array}$ & $2-10$ & $\begin{array}{c}2.56,3.32,3.91 \\
5.81,7.82\end{array}$ & 4.62 & -45 \\
\hline 11 & Two ports & 3-switches & Electrical & $3.1-12$ & $3.9,5.5,7.9$ & ---- & $\leq-20$ \\
\hline 12 & Two ports & $\begin{array}{l}\text { 1-varactor } \\
\text { diode }\end{array}$ & Electrical & $2.5-11.8$ & $\begin{array}{l}5.1,5.2,5.3 \\
5.51,5.6,5.8\end{array}$ & 2.72 & -22 \\
\hline 13 & Single port & $\begin{array}{l}\text { 7-PIN } \\
\text { diodes }\end{array}$ & Electrical & $3-11$ & $\begin{array}{c}6.11,6.52,7.15 \\
7.6,8.2\end{array}$ & 5.4 & ------ \\
\hline 15 & Single port & 6-switches & Electrical & $3.1-12$ & $\begin{array}{l}3.5,5.8,6.5 \\
7.5,8.5,10.3\end{array}$ & ---- & ------- \\
\hline 16 & Single port & 4-switches & Electrical & $3-10$ & $\begin{array}{l}2.46-4.64 \\
4.23-6.65\end{array}$ & 4.14 & ------- \\
\hline 20 & Four ports & $\begin{array}{c}\text { 8-PIN } \\
\text { diodes and } \\
\text { 4-varactor } \\
\text { diodes }\end{array}$ & Electrical & ------- & 0.743 to 2.4 & 3.52 & $\leq-15$ \\
\hline $\begin{array}{l}\text { Proposed } \\
\text { CR Ant. }\end{array}$ & Two ports & $\begin{array}{l}\text { 1-PIN } \\
\text { diode }\end{array}$ & Electrical & $2.72-23.8$ & $\begin{array}{c}7.925,13.16 \\
14.48\end{array}$ & 8.5 & -29 \\
\hline
\end{tabular}

\section{CONCLUSION}

A new compact Tri-band CR antenna for wireless communication applications is presented in this paper with a compact size to meet the requirements for several wireless applications. The proposed structure operates with only a single PIN diode to obtain three resonant frequency bands appropriate for various wireless devices application. The proposed structure can be fabricated simply due to a compact size and planar structure, good characteristics such as gain, efficiency, radiation pattern, return loss less than (-20 dB), coupling less than $(-20 \mathrm{~dB})$, and VSWR less than or equal to (2). The system can be fabricated in the nearest future in order to compare the obtained results from the simulation with the fabricated one.

\section{ACKNOWLEDGEMENTS}

The authors thank Al-Mustansiriyah University for the support and the opportunity of work.

\section{REFERENCES}

[1] Y. Tawk, M. Bkassiny, G. El-Howayek, S. K. Jayaweera, K. Avery and C. G. Christodoulou, "Reconfigurable front-end antennas for cognitive radio applications," inIET Microwaves, Antennas \& Propagation, vol. 5, no. 8, pp. 985-992, 6 June 2011.

[2] M. Al-Husseini, Y. Tawk, C. G. Christodoulou, K. Y. Kabalan and A. El Hajj, "A reconfigurable cognitive radio antenna design," 2010 IEEE Antennas and Propagation Society International Symposium, Toronto, ON, pp. 1-4, 2010.

[3] S. Sharma, C. C. Tripathi and R. Rishi, "Cognitive Radio: An efficient and effective solution for future spectrum implications," 2017 International Conference on Computer, Communications and Electronics (Comptelix), Jaipur, pp. 112-117, 2017.

[4] Z. Aizaz and P. Sinha, "A survey of cognitive radio reconfigurable antenna design and proposed design using genetic algorithm," 2016 IEEE Students' Conference on Electrical, Electronics and Computer Science (SCEECS), Bhopal, pp. 1-6, 2016.

[5] M. Abirami and A. Vimala, "A review of various antenna design methods for cognitive radio application," 2017 th International Conference on Electronics and Communication Systems (ICECS), Coimbatore, pp. 117-120, 2017.

[6] P. B. Nayak, S. Verma and P. Kumar, "Ultrawideband (UWB) antenna design for cognitive radio," 20125 th International Conference on Computers and Devices for Communication (CODEC), Kolkata, pp. 1-4, 2012.

[7] R. M. C. Cleetus and G. J. Bala, "Frequency reconfigurable antennas: A review," 2017 International Conference on Signal Processing and Communication (ICSPC), Coimbatore, pp. 160-164, 2017.

[8] C. G. Christodoulou, "Reconfigurable antennas in cognitive radio that can think for themselves?," 2009 3rd IEEE International Symposium on Microwave, Antenna, Propagation and EMC Technologies for Wireless Communications, Beijing, pp. k-1-k-3, 2009.

[9] Y. Tawk, J. Costantine and C. G. Christodoulou, "A rotatable reconfigurable antenna for cognitive radio applications," 2011 IEEE Radio and Wireless Symposium, Phoenix, AZ, pp. 158-161, 2011.

[10] P. Tummas, P. Krachodnok and R. Wongsan, "A frequency reconfigurable antenna design for UWB applications," 2014 11th International Conference on Electrical Engineering/Electronics, Computer, Telecommunications and Information Technology (ECTI-CON), Nakhon Ratchasima, pp. 1-4, 2014. 
[11] G. Jin, Houbi Liao and Dan Liu, "A dual-port frequency reconfigurable antenna for cognitive radio applications," 2016 IEEE International Conference on Computational Electromagnetics (ICCEM), Guangzhou, pp. 292-294, 2016.

[12] Falih M. Alnahwi, Abdulghafor A. Abdulhameed, Abdulkareem S. Abdullah, "A Compact Integrated UWB/Reconfigurable Microstrip Antenna for Interweave Cognitive Radio Applications", International Journal on Communications Antenna and Propagation (I.Re.C.A.P.), vol 8, no. 1. pp. 81-86. 2018.

[13] M. Al-Husseini, A. Ramadan, M. E. Zamudio, C. G. Christodoulou, A. El-Hajj and K. Y. Kabalan, "A UWB antenna combined with a reconfigurable bandpass filter for cognitive radio applications," 2011 IEEE-APS Topical Conference on Antennas and Propagation in Wireless Communications, Torino, pp. 902-904, 2011.

[14] A. Mansoul and F. Ghanem, "Frequency and bandwidth reconfigurable monopole antenna for cognitive radios," 2013 IEEE Antennas and Propagation Society International Symposium (APSURSI), Orlando, FL, pp. 680-681, 2013.

[15] E. J. B. Rodrigues, H. W. C. Lins and A. G. D'Assunção, "Reconfigurable circular ring patch antenna for UWB and cognitive radio applications," The 8th European Conference on Antennas and Propagation (EuCAP 2014), The Hague, pp. 2744-2748, 2014.

[16] N. Kumar, P. A. Raju and S. K. Behera, "Frequency reconfigurable microstrip antenna for cognitive radio applications," 2015 International Conference on Communications and Signal Processing (ICCSP), Melmaruvathur, pp. 0370-0373, 2015.

[17] G. Srivastava, A. Mohan and A. Chakrabarty, "Compact Reconfigurable UWB Slot Antenna for Cognitive Radio Applications," in IEEE Antennas and Wireless Propagation Letters, vol. 16, pp. 1139-1142, 2017.

[18] G. A. Devi, J. Aarthi, P. Bhargav, R. Pandeeswari, M. A. Reddy and R. S. Daniel, "UWB frequency reconfigurable patch antenna for cognitive radio applications," 2017 IEEE International Conference on Antenna Innovations \& Modern Technologies for Ground, Aircraft and Satellite Applications (iAIM), Bangalore, pp. 1-4, 2017.

[19] P. Chaudhary and S. Verma, "A Swtichable Frequency Reconfigurable UWB Antenna for Cognitive Radio Application," 2018 Second International Conference on Electronics, Communication and Aerospace Technology (ICECA), Coimbatore, pp. 1174-1177, 2018.

[20] R. Hussain and M. S. Sharawi, "4-element planar MIMO reconfigurable antenna system for cognitive radio applications," 2015 IEEE International Symposium on Antennas and Propagation \& USNC/URSI National Radio Science Meeting, Vancouver, BC, pp. 717-718, 2015.

[21] R. Hussain and M. S. Sharawi, "A Cognitive Radio Reconfigurable MIMO and Sensing Antenna System," in IEEE Antennas and Wireless Propagation Letters, vol. 14, pp. 257-260, 2015.

[22] Y. Tawk, F. Ayoub, C. G. Christodoulou and J. Costantine, "A MIMO cognitive radio antenna system," 2013 IEEE Antennas and Propagation Society International Symposium (APSURSI), Orlando, FL, pp. 572-573, 2013.

[23] S. Cheng and K. Lin, "A reconfigurable monopole MIMO antenna with wideband sensing capability for cognitive radio using varactor diodes," 2015 IEEE International Symposium on Antennas and Propagation \& USNC/URSI National Radio Science Meeting, Vancouver, BC, pp. 2233-2234, 2015.

[24] K. Jassim and R. H. Thaher, "Design and analysis of broadband elliptical microstrip patch antenna for wireless communication," Telkomnika (Telecommunication Comput. Electron. Control), vol. 16, no. 6, pp. 2492-2499, 2017.

[25] K. Jassim and R. H. Thaher, "Enhancement Gain of broadband Elliptical Microstrip Patch Array Antenna with Mutual Coupling for Wireless Communication", Indonesian Journal of Electrical Engineering and Computer Science, vol. 13, no. 1, pp. 401-408, March 2019.

[26] T. F. A. Nayna, A. K. M. Baki and F. Ahmed, "Comparative study of rectangular and circular microstrip patch antennas in X band," 2014 International Conference on Electrical Engineering and Information \& Communication Technology, Dhaka, pp. 1-5, 2014.

[27] Skyworks, "DSM8100-000: mesa beam-lead pin diode," Skyworks Solutions, Inc, [Online], Available: www.skyworksinc.com, 2008. 